\title{
Fever treatment and household wealth: the challenge posed for rolling out combination therapy for malaria
}

\author{
J. D. Njau', C. Goodman², S. P. Kachur', , N. Palmer², R. A. Khatib', S. Abdulla', A. Mills ${ }^{2}$ and P. Bloland ${ }^{4}$ \\ 1 Ifakara Health Research and Development Center, Ifakara, Tanzania \\ 2 London School of Hygiene and Tropical Medicine, London, UK \\ 3 Centers for Disease Control and Prevention Malaria Programme in Tanzania, Ifakara, Tanzania \\ 4 Division of Parasitic Diseases, Centers for Disease Control and Prevention, Atlanta, GA, USA
}

Summary oвJестіve To investigate the variation in malaria parasitaemia, reported fever, care seeking, antimalarials obtained and household expenditure by socio-economic status (SES), and to assess the implications for ensuring equitable and appropriate use of antimalarial combination therapy. METHODS A total of 2500 households were surveyed in three rural districts in southern Tanzania in mid-2001. Blood samples and data on SES were collected from all households. Half the households completed a detailed questionnaire on care seeking and treatment costs. Households were categorised into SES thirds based on an index of household wealth derived using principal components analysis. RESULTS Of individuals completing the detailed survey, $16 \%$ reported a fever episode in the previous 2 weeks. People from the better-off stratum were significantly less likely to be parasitaemic, and significantly more likely to obtain antimalarials than those in the middle or poor stratum. The better treatment obtained by the better off led them to spend two to three times more than the middle and poor third spent. This reflected greater use of non-governmental organisation (NGO) facilities, which were the most expensive source of care, and higher expenditure at NGO facilities and drug stores.

CONCLUSION The coverage of appropriate malaria treatment was low in all SES groups, but the two poorer groups were particularly disadvantaged. As countries switch to antimalarial combination therapy, distribution must be targeted to ensure that the poorest groups fully benefit from these new and highly effective medicines.

keywords antimalarials, combination therapy, equity, household, malaria, socio-economic status

\section{Introduction}

There have been increasing calls for better analysis of the equity of access to and use of treatment for common but potentially serious illnesses such as malaria (Barat et al. 2004). A few studies are available on socio-economic status (SES) and treatment seeking for fever (Filmer 2002; Armstrong Schellenberg et al. 2003). However, information is very limited on the relationship between SES and the appropriateness of care obtained and household costs, although the latter may be central in explaining treatment patterns.

Expanding the equitable coverage of appropriate malaria treatment is a key priority in Africa in the context of the Abuja target of $60 \%$ coverage of appropriate antimalarial treatment in vulnerable groups (WHO/UNICEF 2003). Moreover, in the face of increasing drug resistance problems, policymakers are concerned not just about the proportion of care seekers obtaining antimalarials, but also the proportion obtaining effective antimalarials. Growing antimalarial resistance has led many African governments to abandon chloroquine as first line treatment in favour of other monotherapies, such as sulphadoxine/pyrimethamine $(\mathrm{SP})$, and increasingly governments are choosing artemisinin-based combination therapy (ACT). ACT is currently 10-20 times more expensive than widely used monotherapies, but is highly efficacious. Moreover, evidence from Thailand has demonstrated the potential of ACT to slow the development of resistance to the component drugs (White et al. 1999), although experience from Africa remains very limited.

Tanzania represents a relatively typical East African setting. The first line antimalarial treatment was changed to SP in August 2001, and the introduction of ACT is planned for 2006. A recent review reported that Tanzania was unlikely to achieve the Abuja target for malaria treatment (Malaria Consortium 2004), and little is known about the equity of current treatment patterns. To assess 
the nature of the challenge involved in achieving high and equitable levels of coverage with ACT, analysis of the relationship between current provision and SES is necessary. We present data on the relationship between SES and care seeking, antimalarials obtained and household expenditure, collected using a cross-sectional household survey in three rural districts in south-eastern Tanzania. The implications of the findings for strategies to ensure equitable and appropriate use of ACT are considered.

\section{Methods}

\section{Study Sites}

The data were collected as part of the Interdisciplinary Monitoring Project for Antimalarial Combination Therapy in Tanzania ${ }^{a}$. Kilombero, Ulanga and Rufiji Districts are located in Morogoro and Coast Regions in south-eastern Tanzania, 150-400 km from Dar-es-Salaam. They are geographically contiguous, but the Rufiji population is separated from those in Kilombero and Ulanga by the Selous Game Reserve. Median monthly household expenditure was under US\$ 100 in these regions in 2002, and about $75 \%$ of expenditure was on food (United Republic of Tanzania, National Bureau of Statistics (2003))

(INDEPTH Network 2002). The main economic activity is subsistence farming, supplemented by fishing and limited cash-cropping. Many households migrate temporarily during the main cultivation season to second houses close to their farms.

There are typically two rainy seasons, the short rains in October-December and the long rains in March-May, although there is a year-to-year variation. Plasmodium falciparum malaria transmission is intense and perennial in all three districts, but there is seasonal variation reflecting the rainfall patterns. Uncomplicated malaria is the leading diagnosis for outpatient visits in all districts, and acute febrile illness (including malaria) is a major cause of

\footnotetext{
a The Interdisciplinary Monitoring Project for Antimalarial Combination Therapy in Tanzania (IMPACT-Tz) is a multiyear implementation research evaluation project that rests on a collaborative platform comprising the US Public Health Service Centers for Disease Control and Prevention (CDC), Ifakara Health Research and Development Centre, the National Institute for Medical Research, Muhimbili University College of Health Sciences, the London School of Hygiene and Tropical Medicine (UK), and the Tanzanian Ministry of Health, including its National Malaria Control Programme, the Tanzania Essential Health Interventions Project, the Adult Morbidity and Mortality Project, and the Council Health Management Teams of Rufiji, Morogoro, Kilombero and Ulanga Districts. IMPACT-Tz is primarily supported by funding from CDC, the United States Agency for International Development and Wellcome Trust.
}

mortality (INDEPTH Network 2002). Chloroquine resistance is very high, with total treatment failure ${ }^{\mathrm{b}}$ in under fives of $72 \%$ in Kilombero in 1999 (Ministry of Health 1999). Resistance to SP was much lower, with treatment failure of $6.8 \%$ in Rufiji and $6.3 \%$ in Ulanga in 2001 (MacArthur J.R. et al., unpublished data, IMPACT collaboration).

The household survey was conducted in two areas covered by demographic surveillance systems (DSS). The first in Rufiji District contained 31 villages with a population of 73839 in 2001, and the second in Kilombero and Ulanga Districts contained 25 villages with a population of 66503 . These rural populations were served by a mixture of government and non-governmental organisation (NGO) hospitals, health centres and smaller dispensaries, and drugs were also widely available from drug stores and general shops. The NGO facilities were owned by Christian organisations, except for one owned by an Islamic notfor-profit organisation. There were no private for-profit facilities in the study areas. As in most of rural Tanzania, malaria diagnosis in the majority of healthcare facilities and shops is based on the clinical symptoms alone, relying mainly on reported fever. Government facilities are officially free in Rufiji, but in Kilombero and Ulanga user fees have been introduced in dispensaries (but not in health centres). The Integrated Management of Childhood Illness (IMCI) was implemented in formal facilities in Rufiji from 1997, encompassing health worker guidelines, 11-day training courses for staff treating children and system support through improved supervision and commodity supplies (Armstrong Schellenberg et al. 2004). Standard case management remained in place in Kilombero and Ulanga districts until 2002 when the IMCI model was adopted in these areas as well.

\section{Ethical approval and informed consent}

The study received ethical approval from the institutional review boards of the Ifakara Health Research and Development Centre, the Tanzanian Medical Research Coordinating Committee, the London School of Hygiene and Tropical Medicine, and the US Centers for Disease Control and Prevention. Before the start of all interviews, interviewees were informed about the purpose of the research and the nature of their participation. Written consent was obtained from each interviewee, or from parents or guardians on behalf of children. Sub-village leaders and staff of the Council Health Management Teams (CHMT) in each district were also informed.

\footnotetext{
b Total treatment failure includes parasitologic or clinical failure within 14 days of treatment.
} 


\section{Sample selection}

A total of 2500 households was randomly selected, 1250 from Kilombero/Ulanga DSS and 1250 from Rufiji DSS, drawing on the DSS household sampling frames. All residents in each selected household were invited to participate. A questionnaire was completed for each household head and each resident (based on reports by the primary caretaker for children under 12 years). To test for malaria parasitaemia, finger prick blood samples were obtained from each consenting household member for thick and thin blood films, which were read by experienced microscopists at central laboratories in Kilombero and Rufiji. Households where one or more members were not present were revisited once. Households that had closed, declined participation, or where individuals were not present on a second visit were not replaced.

At the time of selection, $50 \%$ of households were randomly assigned to complete a more detailed questionnaire on care-seeking behaviour and treatment costs. The results reported are drawn from this sub-sample (sample of 625 households in each DSS area), with the exception of measures of relative household SES, which were calculated across the whole sample.

\section{Data collection}

The survey was piloted in villages outside the DSS areas, and all interviews were conducted in Swahili. Data were collected by DSS staff between late May and September 2001 , shortly after the season of heaviest rains. The overall completion rate was $92 \%$ in Kilombero/Ulanga, and $83 \%$ in Rufiji. In total, data were obtained for 2191 households, of which 1101 were assigned the detailed questionnaire, which was completed for 3851 individuals.

The questionnaire covered household and individual characteristics and the incidence of 'fever or malaria' in the previous 2 weeks. ${ }^{\mathrm{c}}$ The biomedical concept of uncomplicated malaria overlaps with the local illness concepts of homa (usually translated as fever, although it can include other symptoms), and maleria or homa ya maleria (Winch et al. 1996; Minja et al. 2001). Respondents were therefore asked if they had experienced an episode of homa or maleria. Individuals assigned to the detailed questionnaire reporting fever or malaria were asked about the perceived severity of the episode, associated symptoms, treatment providers visited, care obtained and costs incurred. The definition of provider was broad, including health facilities, shops, traditional healers and any other sources used.

\footnotetext{
${ }^{c}$ Including episodes which began more than 2 weeks previously that continued into the recall period.
}

\section{Data management and analysis}

Data were double entered using FOXPRO 2.6a (Microsoft Inc., Redmond, WA, USA), and checked for completeness, logical consistency and coding errors. Analysis was performed in STATa version 8 (Stata Corp., College Station, TX, USA), using survey commands (e.g. svytab, svymean) to adjust for clustering between individuals in the same household, and because separate samples were drawn from Kilombero/Ulanga and Rufiji DSS systems. Population weights were not used, as the sampling fractions in the two DSS areas were almost equal $2.8 \%$ of the total DSS population were interviewed in Kilombero/Ulanga and $2.7 \%$ in Rufiji). Differences in proportions were tested for significance using the Pearson's chi-squared statistic with the Rao and Scott second-order correction to allow for survey design. Regression analysis was performed using the Huber/White/Sandwich estimators of variance (Stata Inc. 2003).

We assessed the proportion of individuals reporting fever/malaria who obtained an antimalarial and an 'effective' antimalarial, the latter excluding chloroquine because of the high levels of resistance to this drug. Adequate dosing was assessed on the basis of the proportion of individuals obtaining at least a minimum dose according to age-specific national treatment guidelines or IMCI standard dose recommendation guidelines. Where individuals obtained more than one antimalarial of the same generic type (e.g. two sets of chloroquine tablets, or quinine tablets and quinine injections), the doses were summed to assess adequacy. The frequency of over-dosing and the timing of doses were not assessed, as data were collected on drugs obtained from providers, rather than those consumed.

\section{Measuring socio-economic status}

A relative index of household SES was derived based on 19 dichotomous variables using principal components analysis (PCA) (Filmer \& Pritchett 2001; McKenzie 2003). This technique generates an index providing maximum discrimination between households, which is normally distributed with a mean of zero and SD of one. The variables included were a combination of household construction (walls, roof and floor), utilities (sources of water, light and cooking fuel, use of toilet), and ownership of assets (livestock, bed, clock/watch, mattress, iron, mosquito net, radio, clothing cupboard, bicycle, sofa, motorbike and car/ tractor).

The index was calculated across all surveyed households. The first principal component explained $21 \%$ of the variability in the SES variables, a similar proportion to that 
explained in other such analyses (Filmer \& Pritchett 2001; Armstrong Schellenberg et al. 2003; McKenzie 2003). All variables had the expected positive association with SES, with the exception of having a private water supply. It is possible that this may reflect a higher probability of sharing a water supply in areas of higher population density, where households may tend to be relatively better-off. The assets which made the greatest change to the PCA score were ownership of a sofa or clothing cupboard, floor construction and cooking fuel (Table 1).

The PCA scores ranged from -2.46 to 8.67 . Households were classified on the basis of their PCA score into SES thirds of poorest, middle or better-off, with mean PCA scores of $-1.6,-0.6$ and 2.2, respectively. SES thirds rather than quintiles or deciles were used because the distribution of PCA scores was highly skewed to the left making it difficult to make fine distinctions between the SES status of poorer households. SES data were incomplete for 46 households and 154 individuals assigned the detailed questionnaire (4\%), of whom 29 (18.3\%) had reported fever/malaria. Throughout the paper, results are presented only for the individuals with complete SES information.

Principal components analysis scores were not adjusted for household size, as the benefits of household construc- tion, utilities and many durable assets were available at the household level (McKenzie 2003). Average household size was slightly higher among households of higher SES, meaning that, although households were equally distributed between SES thirds by definition, 37\% of individuals interviewed were in the better-off third, compared with $30 \%$ in the poorest third.

\section{Results}

Basic characteristics of households and individuals completing the detailed survey are presented in Table 2 by SES. Households where the head's main occupation was offfarm had significantly higher PCA scores than those mainly engaged in farming, with $23 \%$ of households in the betteroff third mainly engaged in off-farm activities, and only $3 \%$ in the poorest third. There was a significant correlation between the years of education of household head and PCA score $(r=0.4, t$-test, $P<0.0001)$, with $18 \%$ of household heads in the better-off third having more than primary education, compared with only $3 \%$ in the poorest third. There were no significant differences between the two DSS areas in the proportion of households in each SES third, or in the mean PCA score; nor were there significant

\begin{tabular}{lllll}
\hline Variable definition* & Mean & SD & Weight & Impact on PCA score $\dagger$ \\
\hline Floor of tiles/cement & 0.12 & 0.322 & 0.35 & 1.09 \\
Walls of fired bricks/cement & 0.21 & 0.409 & 0.27 & 0.66 \\
Roof of tiles/cement/corrugated iron & 0.26 & 0.437 & 0.31 & 0.71 \\
Cooking fuel is electricity/ & 0.09 & 0.284 & 0.30 & 1.06 \\
gas/kerosene/charcoal & & & & \\
Water source is private pipe, & 0.18 & 0.383 & -0.05 & -0.13 \\
well or pump & & & & \\
Household has use of toilet & 0.97 & 0.169 & 0.03 & 0.18 \\
Light source is electricity/ & 0.14 & 0.351 & 0.31 & 0.88 \\
hurricane lamp & & & & \\
Household owns at least one: & & & & \\
Bed & 0.95 & 0.224 & 0.07 & 0.31 \\
Watch/clock & 0.35 & 0.476 & 0.24 & 0.50 \\
Mattress & 0.33 & 0.469 & 0.32 & 0.68 \\
Iron & 0.11 & 0.314 & 0.28 & 0.89 \\
Mosquito net & 0.54 & 0.499 & 0.16 & 0.32 \\
Radio & 0.49 & 0.500 & 0.24 & 0.48 \\
Clothing cupboard & 0.05 & 0.217 & 0.28 & 1.29 \\
Bicycle & 0.44 & 0.496 & 0.17 & 0.34 \\
Livestock & 0.58 & 0.494 & 0.05 & 0.10 \\
Sofa & 0.04 & 0.201 & 0.28 & 1.39 \\
Motorbike & 0.005 & 0.068 & 0.01 & 0.15 \\
Car & 0.003 & 0.053 & 0.04 & 0.75 \\
\hline
\end{tabular}

Table I Results of principal components analysis of household socio-economic status (SES) variables

* Households were allocated one if at least some of their construction materials or light/ cooking fuel fell in these categories.

$\dagger$ Impact of a change from 0 to 1 for each variable (weight/SD). 
J. D. Njau et al. Fever treatment and household wealth

Table 2 Characteristics of household survey respondents by socio-economic status (SES)

\begin{tabular}{|c|c|c|c|c|c|}
\hline & \multicolumn{5}{|l|}{ SES thirds } \\
\hline & Poorest (\%) & Middle (\%) & Better-off $(\%)$ & Total $(\%)$ & $P$-value \\
\hline \multicolumn{6}{|l|}{ Household characteristics } \\
\hline Number of households $\dagger$ & 362 & 343 & 350 & 1055 & \\
\hline \multicolumn{6}{|c|}{ Main job of household headt: } \\
\hline Farming & $352(98)$ & $316(92)$ & $267(76)$ & $935(89)$ & \multirow[t]{3}{*}{$<0.0001^{*}$} \\
\hline Off-farm work & $9(3)$ & $25(7)$ & $81(23)$ & $115(11)$ & \\
\hline None & $0(-)$ & $1(0.3)$ & $2(0.6)$ & $3(0.3)$ & \\
\hline \multicolumn{6}{|l|}{ Education of household head: } \\
\hline None & $128(37)$ & $115(35)$ & $68(20)$ & $311(31)$ & \multirow[t]{4}{*}{$<0.0001^{*}$} \\
\hline Some primary & $112(33)$ & $99(30)$ & $79(24)$ & $290(29)$ & \\
\hline Completed primary only & $95(28)$ & $101(32)$ & $130(39)$ & $329(33)$ & \\
\hline More than primary & $9(3)$ & $12(4)$ & $59(18)$ & $80(8)$ & \\
\hline \multicolumn{6}{|l|}{ Religion of household head: } \\
\hline Christian & $159(44)$ & $124(36)$ & $133(38)$ & $416(39)$ & \multirow[t]{4}{*}{0.1665} \\
\hline Muslim & $199(55)$ & $216(63)$ & $216(62)$ & $631(60)$ & \\
\hline Traditional & $1(0.3)$ & $0(-)$ & $1(0.3)$ & $2(0.2)$ & \\
\hline No religion & $3(0.8)$ & $3(0.9)$ & $0(-)$ & $6(0.6)$ & \\
\hline \multicolumn{6}{|c|}{ Demographic surveillance systems (DSS) area: } \\
\hline Kilombero/Ulanga DSS & $206(57)$ & $177(52)$ & $202(58)$ & $585(55)$ & \multirow[t]{2}{*}{0.2140} \\
\hline Rufiji DSS & $156(43)$ & $166(48)$ & $148(42)$ & $470(45)$ & \\
\hline \multicolumn{6}{|l|}{ Individual characteristics } \\
\hline Number of individuals $\dagger$ & 1139 & 1245 & 1313 & 3697 & \\
\hline \multicolumn{6}{|l|}{ Age group: } \\
\hline Under 5 years & $181(16)$ & $215(17)$ & $201(15)$ & $597(16)$ & \multirow[t]{2}{*}{0.3294} \\
\hline Over 5 years & $956(84)$ & $1029(83)$ & $1112(85)$ & $3097(84)$ & \\
\hline \multicolumn{6}{|l|}{ Gender: } \\
\hline Male & $513(47)$ & $536(45)$ & $578(46)$ & $1627(46)$ & \multirow[t]{2}{*}{0.7033} \\
\hline Female & $584(53)$ & $649(55)$ & $669(54)$ & $1902(54)$ & \\
\hline
\end{tabular}

$\uparrow$ Data were missing on household head education for 45 households, main job for two households, age for three individuals and gender for 168 individuals.

† Off-farm work encompassed labourer, business, driver, craftsman, formal sector, traditional healer, lumberjack, charcoal seller and fishing.

* Significant difference across SES groups (chi-squared test with Rao and Scott's correction, $P<0.05$ ).

differences by SES in religion, age or gender of individuals interviewed.

Of the individuals completing the detailed survey, 599 $(16 \%)$ reported a fever episode in the previous 2 weeks, and 451 of these $(75 \%)$ had visited at least one provider, generating data on 557 provider visits. There was significant variation in reported fever/malaria by age group: episodes were most likely to be reported for under fives $(28 \%)$, followed by adults $(16 \%)$, and least likely for older children (5-14 years) (10\%). There was no difference in reported fever/malaria by SES (Table 3). However, individuals in the better-off third were significantly less likely to be parasitaemic on the day of interview. This difference was particularly pronounced for under fives, of whom $30 \%$ were parasitaemic in the better-off third compared with $45 \%$ and $46 \%$ in the poorest and middle thirds, respectively $(P=0.007)$.
Table 3 also shows treatment sought for reported fever/ malaria by SES. The probability of obtaining some kind of treatment from a provider, home or neighbour was over $80 \%$ for all three SES groups, although the better-off third were somewhat more likely to do so. There was no significant difference by SES in the probability of visiting government facilities, drug stores or general shops. However, households in the better-off third were significantly more likely to use an NGO facility. Similar patterns of care seeking across SES were found within the over-five and under-five age groups; under-fives were more likely than over-fives to visit facilities and less likely to use general stores in all SES groups. Visiting traditional healers or other sources of care was rare for all SES groups.

Only $13 \%$ of individuals visited more than one provider, although two children made five visits each. There was no significant difference in the mean number of visits between 


\section{J. D. Njau et al. Fever treatment and household wealth}

Table 3 Malaria parasitaemia, reported fever/malaria, treatment sources and drugs obtained

\begin{tabular}{|c|c|c|c|c|c|}
\hline & \multicolumn{5}{|l|}{ SES thirds } \\
\hline & Poorest $(\%)$ & Middle $(\%)$ & Better-off $(\%)$ & Total $(\%)$ & $P$-value \\
\hline Number of individuals & 1139 & 1245 & 1313 & 3693 & \\
\hline Plasmodium falciparum parasitaemia on the day of interview & $249(25)$ & $283(26)$ & $202(18)$ & $734(23)$ & $0.0001 *$ \\
\hline Reported fever/malaria in previous 2 weeks $\dagger$ & $179(16)$ & $212(17)$ & $208(16)$ & $599(16)$ & 0.6863 \\
\hline \multicolumn{6}{|l|}{ Of individuals reporting fever/malaria } \\
\hline Any treatment & $149(83)$ & $170(80)$ & $190(91)$ & $509(85)$ & $0.0067^{*}$ \\
\hline Any provider visit & $133(74)$ & $156(74)$ & $162(78)$ & $451(75)$ & 0.5594 \\
\hline Visited government facility & $43(24)$ & $45(21)$ & $48(23)$ & $136(23)$ & 0.8103 \\
\hline Visited NGO facility & $5(3)$ & $7(3)$ & $27(13)$ & $39(7)$ & $<0.0001 *$ \\
\hline Visited any facility & $47(26)$ & $51(24)$ & $72(35)$ & $170(28)$ & 0.0647 \\
\hline Visited drug store & $51(28)$ & $51(24)$ & $57(27)$ & $159(27)$ & 0.6380 \\
\hline Visited general shop & $53(30)$ & $72(34)$ & $54(26)$ & $179(30)$ & 0.2501 \\
\hline Visited traditional healer & $2(1)$ & $2(1)$ & $0(-)$ & $4(0.7)$ & 0.3308 \\
\hline Visited other provider & $1(1)$ & $0(-)$ & $3(1)$ & $4(0.7)$ & 0.2831 \\
\hline Obtained drug from home/neighbour & $20(11)$ & $20(9)$ & $35(17)$ & $75(13)$ & 0.0763 \\
\hline \multicolumn{6}{|l|}{ Drugs obtained } \\
\hline Antimalarial & $53(31)$ & $70(34)$ & $91(46)$ & $214(37)$ & $0.0118 *$ \\
\hline Adequate antimalarial dose & $38(23)$ & $47(23)$ & $68(35)$ & $153(27)$ & $0.0186 *$ \\
\hline Effective antimalarial & $18(11)$ & $25(12)$ & $48(24)$ & $91(16)$ & $0.0009 *$ \\
\hline Adequate dose of effective antimalarial & $14(8)$ & $13(6)$ & $38(19)$ & $65(11)$ & $0.0001 *$ \\
\hline
\end{tabular}

$\dagger$ Data were missing on reported fever/malaria for four individuals.

* Significant difference across SES groups (chi-squared test with Rao and Scott's correction, $P<0.05$ ).

the SES thirds. Of the 599 people reporting fever/malaria only four $(0.7 \%)$ were admitted, one at a government health centre, two at mission hospitals and one at a mission dispensary. Of these admissions, two were in the better-off third, one in the middle and one in the poorest third.

Individuals in the better-off third were significantly more likely to receive antimalarials than those in the middle or poorest third, and this differential was even more pronounced when only effective antimalarials were considered
(Table 3). Of all antimalarials dispensed, the proportion under-dosed did not vary significantly by SES $(28 \%$ of antimalarials obtained by the poorest third, $34 \%$ by the middle third and $29 \%$ by the better-off third, $P=0.7$ ). As a result, the probability of obtaining an adequate antimalarial dose across SES groups followed a similar pattern to that of obtaining any antimalarials. Antimalarials were most likely to be obtained during visits to NGO facilities and least likely at general stores (Figure 1). They were

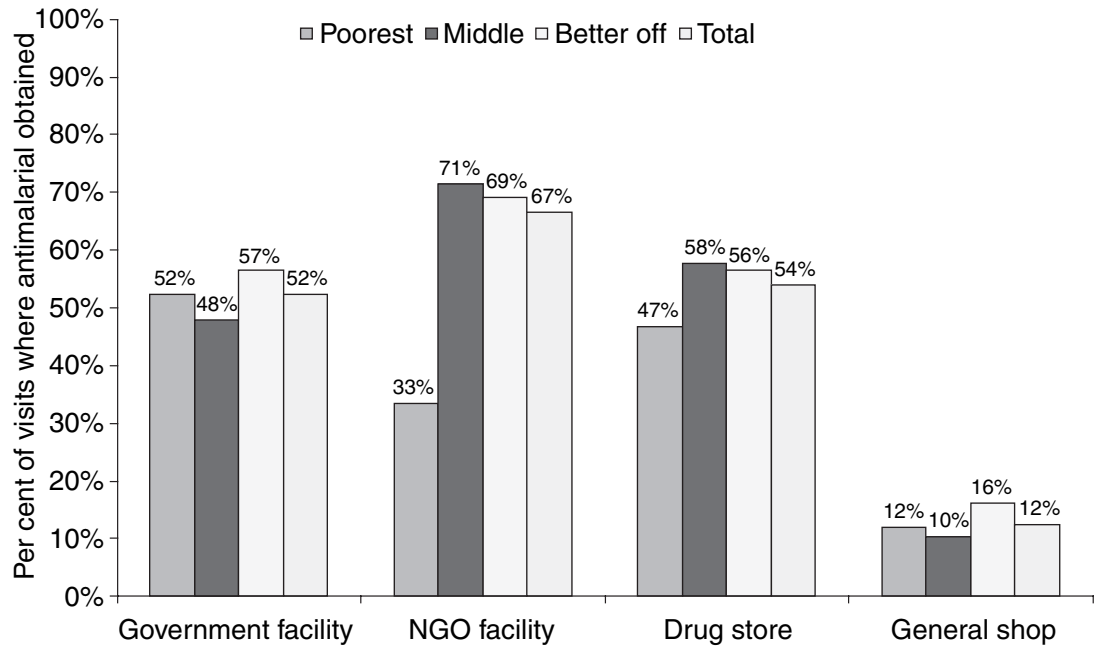

Figure I Probability of obtaining an antimalarial drug at provider visits. 


\section{J. D. Njau et al. Fever treatment and household wealth}

Table 4 Travel time to providers and mode of transport by SES

\begin{tabular}{|c|c|c|c|c|c|}
\hline & \multicolumn{5}{|l|}{ SES thirds } \\
\hline & $\begin{array}{l}\text { Poorest } \\
(\%)\end{array}$ & $\begin{array}{l}\text { Middle } \\
(\%)\end{array}$ & $\begin{array}{l}\text { Better-off } \\
(\%)\end{array}$ & $\begin{array}{l}\text { Total } \\
(\%)\end{array}$ & $P$-value \\
\hline $\begin{array}{l}\text { Number of provider visits } \\
\text { where travel time known }\end{array}$ & 149 & 183 & 194 & 526 & \\
\hline Travel time under $1 \mathrm{~h} \dagger$ & $114(77)$ & $145(79)$ & $177(91)$ & $436(83)$ & $0.0134 *$ \\
\hline \multicolumn{6}{|l|}{ Mode of transport } \\
\hline Travel on foot & $126(85)$ & $139(76)$ & $133(69)$ & $398(76)$ & $0.0314 *$ \\
\hline Travel by bicycle & $23(15)$ & $40(22)$ & $53(27)$ & $116(22)$ & \\
\hline Public transport & $0(-)$ & $4(2)$ & $8(4)$ & $12(2)$ & \\
\hline
\end{tabular}

$\uparrow$ Data were missing on travel time for 29 visits; also excludes two cases where lymphatic filariasis project workers visited the patients at home.

* Significant difference across SES groups (chi-squared test with Rao and Scott's correction, $P<0.05)$.

provided at only just over a half of visits to both government facilities and drug stores.

Treatment seeking was rapid in all SES groups: $78 \%$ of first visits took place within $24 \mathrm{~h}$ of the onset of fever/ malaria symptoms, with no significant difference across SES groups $(P=0.5)$. On average, the better-off third had shorter travel times to providers, being significantly more likely to reach providers within an hour than the poorest (Table 4). The better-off were more likely to travel by bicycle and public transport, although the majority in all groups went by foot. Care seekers spent significantly longer time at both government and NGO facilities than at shops; $40 \%$ and $39 \%$ of visits at government and NGO facilities, respectively, took longer than an hour, compared with $3 \%$ at drug stores and 0 at general shops. There was no significant relationship between SES and time spent at the providers $(P=0.9)$.

Complete cost information was available for 572 individuals reporting fever/malaria. Of the four individuals admitted, cost data were missing for one individual, with the remaining three spending Tshs. 1000.00 (1.12 USD), 5000.00 (5.60 USD) and 15000.00 (16.85 USD) during their episode ${ }^{\mathrm{d}}$. Subsequent cost data presented include only those not admitted. Of the remaining 569 individuals, 188 $(33 \%)$ spent nothing and there was no significant relationship between the probability of spending nothing and SES. For those spending, expenditure per episode ranged from Tshs. 5.00-4900.00 (0.0056-5.50 USD).

There were significant differences across provider type in mean expenditure per visit (Table 5). Mean expenditure at NGO facilities was three times higher than at drug stores, seven times higher than at government facilities and 16

\footnotetext{
d Tshs. $890.00 \sim 1.00$ USD.
}

Table 5 Cost per visit by provider type (TShs)

\begin{tabular}{lccrr}
\hline & $\begin{array}{l}\text { Number } \begin{array}{l}\text { Mean } \\
\text { of } \\
\text { visits }\end{array} \\
\text { expenditure } \\
(95 \% \text { CI })\end{array}$ & Median Range \\
\hline Government facility & 136 & $193(133-253)$ & 25 & $0-2300$ \\
NGO facility & 34 & $1325(822-1828)$ & 1030 & $0-4800$ \\
Drug store & 153 & $450(343-557)$ & 270 & $0-4500$ \\
General store & 193 & $80(63-98)$ & 40 & $0-1000$ \\
\hline
\end{tabular}

times higher than at general stores. Median expenditure was also highest for NGO facilities, but lowest for government facilities.

The majority of total expenditure in all SES thirds was on drugs (Figure 2). Transport was the second most important cost in all thirds, with the remainder spent on food and lodging and non-drug fees such as registration, consultation, laboratory tests and syringes. No one reported having made any kind of informal payment. However, payments were reported in some government facilities where costsharing had not been introduced, indicating that patients may have been unaware that payments were unofficial.

Table 6 shows the total cost per episode for all individuals and for only those with some expenditure. For all individuals, there was no difference between median expenditure for the poor and middle thirds, but the median for the better-off was more than three times greater. Similarly, the mean expenditure for the poorest and middle thirds was not significantly different, but was significantly higher for the better-off. The same patterns in median and mean expenditure were observed when only those who had incurred some expenditure were considered. The better-off third spent more partly because they were more likely to visit NGO facilities and partly because they spent more at each provider type (Table 3 and Figure 3). 
(a) Poorest third

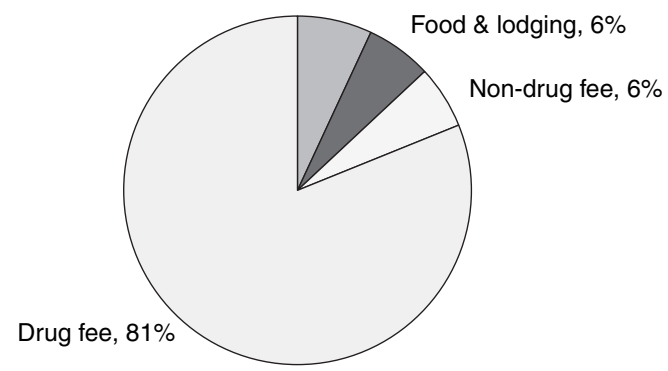

(b) Middle third

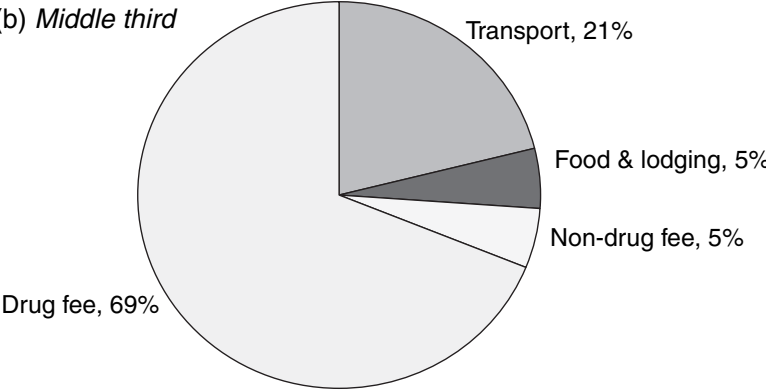

(c) Better Off

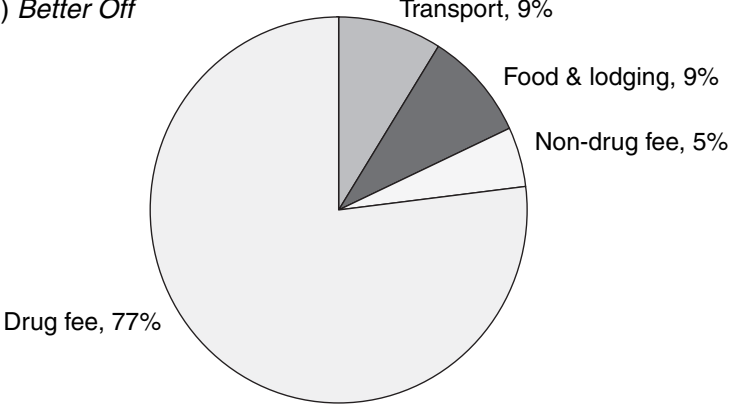

Figure 2 Breakdown of total expenditure by socio-economic status (SES). (a) Poorest third. (b) Middle third. (c) Better-off.

Table 7 shows variation in total cost per episode by other household and individual characteristics. Mean and median expenditures were higher for households in $\mathrm{Ki}$ lombero/Ulanga DSS area, for those with more educated or Christian household heads, where the sick individual was under 5 years or male, and where the illness was perceived as life threatening. On the basis of these bivariate analyses, mean expenditure was significantly related to DSS area, household head education and perceived severity.

Multivariate analysis was used to assess whether SES had a significant impact on expenditure after controlling for these other potential determinants (Table 8). A twopart model of healthcare demand was used to allow for the high proportion of zero cost observations, and the skewed
Table 6 Total cost per episode for all individuals reporting fever/ malaria and for only those with some expenditure (TShs)*

\begin{tabular}{|c|c|c|c|c|}
\hline & $\begin{array}{l}\text { Number } \\
\text { of } \\
\text { episodes }\end{array}$ & $\begin{array}{l}\text { Mean } \\
\text { expenditure } \\
(95 \% \mathrm{CI})\end{array}$ & Median & Range \\
\hline \multicolumn{5}{|c|}{ For all individuals } \\
\hline Poorest & 167 & $152(107-196)$ & 30 & $0-1740$ \\
\hline Middle & 205 & $163(116-210)$ & 30 & $0-3200$ \\
\hline Better-off & 197 & $474(325-623)$ & 100 & $0-4900$ \\
\hline Total & 569 & $267(209-325)$ & 50 & $0-4900$ \\
\hline \multicolumn{5}{|c|}{ For individuals with some expenditure } \\
\hline Poorest & 105 & $241(174-308)$ & 100 & $10-1740$ \\
\hline Middle & 137 & $244(178-310)$ & 100 & $5-3200$ \\
\hline Better-off & 139 & $672(475-868)$ & 200 & $10-4900$ \\
\hline Total & 381 & $399(316-482)$ & 120 & $5-4900$ \\
\hline
\end{tabular}

* Excluding the five admissions.

distribution of expenditure (Mullahy 1998). Firstly, a Logit model of whether any expenditure was made found the only significant explanatory variable to be DSS area, with households in Kilombero/Ulanga DSS 91\% more likely to spend compared with those in Rufiji DSS. SES was not significant. Secondly, a log-linear model of total expenditure per episode for those who spent was estimated. The model included an interaction term between religion and DSS sites in addition to including both variables separately, as DSS area and religion of household head were correlated (correlation coefficient of 0.6 ) and both may be associated with expenditure. Although the interaction term was not statistically significant, its inclusion changed the sign and significance of the coefficient for religion so it was included in the final model. Running the regression separately by DSS area indicated that the change occurred because religion had a larger impact on expenditure in Rufiji than in Kilombero and Ulanga DSS sites.

The log linear model had an $R^{2}$ of 0.2 . Total expenditure per episode was significantly affected by SES (PCA score), DSS area, religion of the household head and perceived severity of illness. An increase of 1 in the PCA score led to a $15 \%$ increase in expenditure. Residence in Kilombero/ Ulanga DSS increased expenditure by $76 \%$ when compared with those in Rufiji DSS, and being a Christian household increased expenditure by $64 \%$. Perceiving the illness as life threatening increased expenditure by $66 \%$. We also tested quadratic terms for education and PCA scores, neither of which were significant.

We investigated the importance of a number of potential strategies to improve affordability for the poor: credit, payment-in-kind and free facility care. Credit was obtained at only five visits $(0.9 \%)$, four at drug stores and one at a government facility. Of the individuals obtaining credit, 


\section{J. D. Njau et al. Fever treatment and household wealth}

Figure 3 Median expenditure by SES per provider visit (TShs).

Table 7 Variation in total cost per episode by household and individual characteristics

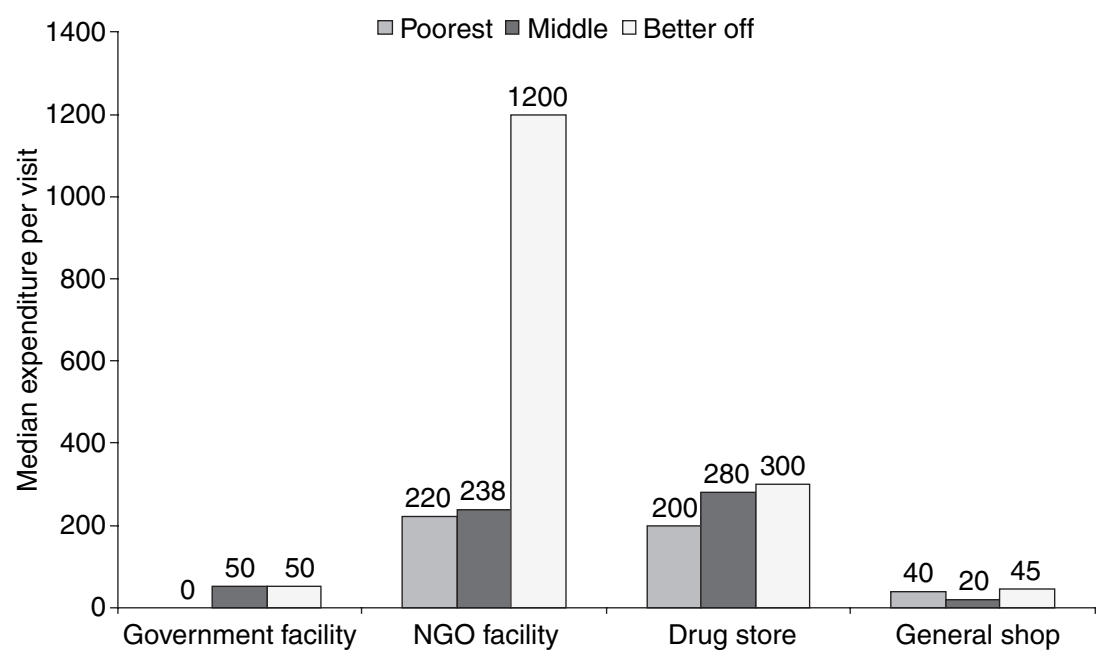

\begin{tabular}{|c|c|c|c|c|}
\hline & $\begin{array}{l}\text { Number } \\
\text { of } \\
\text { episodes* }\end{array}$ & $\begin{array}{l}\text { Mean } \\
(95 \% \text { CI })\end{array}$ & Median & Range \\
\hline \multicolumn{5}{|l|}{ Household characteristics } \\
\hline \multicolumn{5}{|c|}{ Education of household head } \\
\hline None & 156 & $134(58-210)$ & 17.5 & $0-3080$ \\
\hline Some primary & 145 & $184(124-244)$ & 40 & $0-3200$ \\
\hline Completed primary only & 190 & $355(246-465)$ & 100 & $0-4500$ \\
\hline More than primary & 48 & $620(217-1024)$ & 100 & $0-4900$ \\
\hline \multicolumn{5}{|l|}{ DSS area } \\
\hline Kilombero/Ulanga & 273 & $356(265-448)$ & 100 & $0-4900$ \\
\hline Rufiji & 296 & $185(113-257)$ & 20 & $0-4800$ \\
\hline \multicolumn{5}{|l|}{ Religion of household head } \\
\hline Christian & 205 & $313(219-407)$ & 100 & $0-4900$ \\
\hline Muslim & 363 & $239(165-313)$ & 20 & $0-4800$ \\
\hline Traditional & 1 & $1300(-)$ & 1300 & 1300 \\
\hline \multicolumn{5}{|l|}{ Individual characteristics } \\
\hline \multicolumn{5}{|l|}{ Age group } \\
\hline Under 5 years & 154 & $321(214-427)$ & 50 & $0-4900$ \\
\hline Over 5 years & 415 & $248(186-309)$ & 45 & $0-4800$ \\
\hline \multicolumn{5}{|l|}{ Gender } \\
\hline Male & 232 & $257(177-338)$ & 55 & $0-4900$ \\
\hline Female & 307 & $256(182-329)$ & 30 & $0-4800$ \\
\hline \multicolumn{5}{|c|}{ Perceived severity of episode } \\
\hline Life threatening & 139 & $489(315-662)$ & 100 & $0-4900$ \\
\hline Not life threatening & 381 & $202(156-247)$ & 40 & $0-4500$ \\
\hline
\end{tabular}

* Of the 569 individuals with complete cost information (excluding those admitted), data were missing on education for 30 individuals, on gender for 30 individuals and on perceived severity for 49 individuals. two were from the poorest third and three from the betteroff third. Payment-in-kind was even less common with only one occurrence recorded, a supplementary payment to government facility staff in addition to cash payments for drug and non-drug fees. Of the 39 NGO facility visits where drugs were obtained, care was provided free to three $(8 \%)$ individuals, one from each SES third. Of the 119 government facility visits where drugs were obtained, free care was provided at $59(50 \%)$ visits. Individuals were, unsurprisingly, much more likely to obtain free govern- 
J. D. Njau et al. Fever treatment and household wealth

Table 8 Two part model of demand for fever/malaria treatment

\begin{tabular}{|c|c|c|c|c|c|c|}
\hline \multirow[b]{3}{*}{ Explanatory variables } & \multirow{2}{*}{\multicolumn{3}{|c|}{$\begin{array}{l}\text { A: Logit regression model of probability } \\
\text { of having some expenditure } \\
n=486 \& F=0.0142\end{array}$}} & \multirow{2}{*}{\multicolumn{3}{|c|}{$\begin{array}{l}\text { B: Log-linear regression model of total } \\
\text { spending per episode for those with some } \\
\text { expenditure } \\
n=302, R^{2}=0.2183 \& F=0.0001\end{array}$}} \\
\hline & & & & & & \\
\hline & Coefficients & \multicolumn{2}{|c|}{$[95 \% \mathrm{CI}]$} & \multirow{2}{*}{$\begin{array}{l}\text { Coefficient } \\
0.150(0.001 *)\end{array}$} & \multicolumn{2}{|l|}{$[95 \% \mathrm{CI}]$} \\
\hline Principal components analysis (PCA) score & 0.089 & -0.025 & 0.203 & & 0.065 & 0.235 \\
\hline Years of education of the household head & 0.012 & -0.057 & 0.082 & 0.050 & -0.008 & 0.108 \\
\hline Kilombero DSS & $0.905(0.001 *)$ & 0.368 & 1.441 & $0.756(0.004 *)$ & 0.249 & 1.262 \\
\hline Christian household head & -0.383 & -0.939 & 0.174 & $0.635\left(0.045^{*}\right)$ & 0.015 & 1.256 \\
\hline Individual under 5 years & 0.031 & -0.415 & 0.478 & 0.214 & -0.144 & 0.572 \\
\hline Male individual & 0.130 & -0.255 & 0.515 & 0.027 & -0.270 & 0.324 \\
\hline Illness perceived as life threatening & 0.456 & -0.001 & 0.914 & $0.656(<0.001 *)$ & 0.299 & 1.013 \\
\hline DSS $\times$ religion (interaction term) & & & & -0.342 & -1.123 & 0.438 \\
\hline Constant & 0.247 & -0.201 & 0.695 & $3.872(<0.001 *)$ & 3.530 & 4.214 \\
\hline
\end{tabular}

* P-value, statistically significant at 0.05 level.

ment care in Rufiji DSS where official user fees had not been introduced ( $78 \%$ compared with $16 \%$ in Kilombero/ Ulanga DSS). There was little difference in the probability of free government care by SES $(56 \%$ of visits by individuals in the poorest third, $46 \%$ in the middle third and $48 \%$ in the better-off third).

\section{Discussion}

\section{Limitations}

Self-reported 14 day history of fever is a commonly used measure in standardised surveys of child health (WHO 2003; Measure 2005; UNICEF 2005). However, it is subject to a number of limitations. Reporting of both illness episodes and treatment obtained may be subject to incomplete recall over the 2 -week period. Reported treatment may also have been deliberately misrepresented if use of certain providers or medicines is perceived as more socially acceptable. Even in the absence of recall or social desirability bias, there is some controversy over whether caretakers can accurately recognise fever in children. For example, in Guinea, $55 \%$ of children reported as febrile had a normal temperature, and a high temperature was found in $38 \%$ of children identified as sick but afebrile, and in $13 \%$ of children considered healthy (Diallo et al. 2001). In the Tanzanian setting, these issues were potentially compounded by the interpretation of homa. While this term is generally translated as fever, it can apply to a broader range of symptoms, such as respiratory or gastrointestinal illnesses (Winch et al. 1994; Tarimo et al. 2000). In such cases, antimalarial treatment may not have been warranted on the basis of clinical symptoms.
Moreover, of those truly febrile, a high proportion is likely to have been suffering from non-malarial illnesses. Facility surveys in the same areas have shown that only $51 \%$ of outpatients diagnosed with malaria were parasite positive at dispensaries, $39 \%$ at health centres, and $38 \%$ at hospitals (Causer L.M. et al., unpublished data, IMPACT Collaboration). Confirmed parasitological diagnosis is rarely available in such areas, and antimalarial treatment based on the clinical symptoms alone is in accordance with national treatment guidelines. However, one could question whether it is appropriate to treat all mild fevers in adults as malaria cases given that their higher levels of immunity increase the likelihood that these fevers may have non-malarial causes.

These limitations would be a particular cause for concern in this analysis if potential biases were not randomly distributed across socio-economic groups. For example, it is possible that the better-off, more educated group were more likely to report illness, had better recall of treatment obtained, or were more influenced by social desirability bias. Data were collected only on drugs obtained; if adherence to doses obtained varied by SES, relative quality of treatment consumed may have differed from that obtained. However, other studies in these districts have not found SES to affect adherence to treatment obtained (Armstrong Schellenberg et al. 2003; Kachur et al. 2004). It is also possible that fever episodes reported were more likely to have been caused by malaria in poorer groups. Although poorer groups had a higher parasite prevalence on the day of interview, it was not possible to assess whether a higher proportion of their reported fevers was malarial, as some patients who had experienced malaria in the previous 2 weeks would not 
have been parasitaemic by the day of interview, and others who tested positive for parasitaemia may have had lowdensity asymptomatic infections.

Socio-economic status was assessed through an asset index because of the time requirements for collecting household income or expenditure data, and associated problems of recall bias and mismeasurement. An oft-cited advantage of asset indices is that they are not subject to the seasonal variation that affects expenditure and income measures. However, this may have been a disadvantage in this analysis, if treatment choice was influenced by seasonal variation in cash availability, particularly if such variations had a relatively large impact on expenditure patterns and treatment choices for poorer households. Patterns of treatment seeking across SES groups may also have varied seasonally if, during the peak malaria season, the better-off were more likely to avoid long queues at government facilities.

\section{The Impact of SES}

One might have expected variation by SES to be limited, as these rural DSS areas did not include either small towns or major urban centres, nor any of Tanzania's relatively wealthy agricultural regions. However, despite the homogeneity of the study sites, and small sample sizes for some comparisons, SES variation was clearly evident. Firsty, individuals in the better-off third were less likely to be parasitaemic on the day of the interview. Although this did not translate to a lower rate of reported fever/malaria, one would expect it to be related to other health consequences, such as chronic anaemia and low-birth weight.

Secondly, better-off individuals reporting fever/malaria were significantly more likely to obtain antimalarials, and in particular to obtain effective antimalarials. Better treatment resulted in an average expenditure two to three times greater than that in the poorest or middle thirds. The better-off spent more because they were more likely to use NGO facilities, which were the most expensive source of care, and they also tended to spend more at NGO facilities and drug stores. However, their indirect costs of travel time were lower, probably reflecting both their use of faster means of transport, and a tendency for both providers and better-off households to be located in market centres (E. Mwageni, unpublished data, Rufiji DSS). One might have expected NGO facilities to serve the poorest groups preferentially. However, most such facilities were obliged to cover their operating costs fully through user fees, and their charges were therefore higher than those at government facilities. Moreover, most households in the betteroff third would still be considered poor in absolute terms. There were no significant differences between the poorest and middle thirds in terms of treatment, drugs obtained or expenditure, although this may have reflected the limitations of the asset index in distinguishing between the SES status of poorer households.

In addition to variation by SES, expenditure was also significantly influenced by household head religion and DSS area. Christian households were on average not wealthier, but were clustered around mission-owned NGO facilities in both DSS sites, which may explain why they spent more on average than their muslim counterparts. Residents in Kilombero/Ulanga DSS were more likely to obtain antimalarials, and spent significantly more on treatment, than those in Rufiji DSS. The latter's lower costs were partly because of the absence of official fees at government facilities in Rufiji, in contrast to Kilombero/ Ulanga where cost sharing had been introduced in government dispensaries. Lower expenditure in Rufiji also reflected differences in patterns of retail sector use. Rufiji residents reporting fever were more likely to visit general shops than drug stores (35\% vs. 22\%), whereas Kilombero/Ulanga residents were more likely to visit drug stores (24\% general shops vs. $32 \%$ drug shops). Overall, median expenditure was almost seven times greater at drug stores than at general shops. It is possible that greater use of drug shops in Kilombero/Ulanga reflected a greater demand for antimalarials, as a result of the longer history of healthrelated research and social marketing of insecticide-treated nets in these areas.

Several similarities with other published studies can be noted. The finding that SES was positively related to the probability of obtaining antimalarials, but unrelated to fever incidence, is supported by other studies from Tanzania and elsewhere in Africa (Filmer 2002; Armstrong Schellenberg et al. 2003). Declining parasite prevalence with an increasing SES has also been documented among Gambian children (Clarke et al. 2001). The relative cost per visit across provider types followed a pattern similar to that observed in Nigeria and Kenya (Amin et al. 2003; Brieger et al. 2004). However, in contrast to the results from this study, Ettling et al. (Ettling et al. 1994) found no consistent relationship between treatment expenditure and household income in Malawi. This may possibly reflect the much more limited role of private providers in Malawi at the time of the study and/or lower fees at NGO facilities than in Tanzania. It may also be explained by the authors' categorisation of Malawian households into two groups of 'very low income' and 'low to high income', whereas we found that it was the relatively wealthy households that had significantly different behaviour from the majority. In multivariate analysis of the determinants of treatment expenditure for febrile children in rural Benin, Rashed et al. (2000) found expenditure to be positively and 
significantly related to women's income, but not to men's income nor to a household wealth index, indicating that the intra-household distribution of income may also be important in determining treatment received.

An important finding of this study is that the care received in all SES groups was inadequate. The majority relied on inadequate public sector provision and the limited antimalarials they could purchase from the retail sector. Of those who had opted for any treatment, only $24 \%$ of the poorest, $21 \%$ of the middle and $23 \%$ of the better-off third visited any government facility. Moreover, only $8 \%$ of the poorest, $6 \%$ of the middle and $19 \%$ of the better-off third received an adequate dose of effective antimalarials. The relatively better-off obtained better care by paying significantly more to obtain antimalarials and effective antimalarials at NGO facilities and drug stores. Under current patterns of provision, individuals in the poorest and middle thirds would need to triple their average expenditure per episode to reach the still inadequate quality of care currently obtained by the better-off. However, even in the better-off third, under a half of care seekers obtained an antimalarial, and only $19 \%$ obtained an adequate dose of an effective antimalarial. This is clearly a Tanzania-wide problem; the nationally representative Demographic and Health Survey in 1999 found only $52 \%$ of under fives with fever had received an antimalarial (National Bureau of Statistics Tanzania, Macro International Inc. 2000).

It is worth noting that this survey was conducted before and during the malaria treatment policy change in August 2001. During this period, the availability of antimalarial drugs other than chloroquine was highly variable. A subsequent survey conducted in 2002 showed that, while the proportion of people obtaining an antimalarial was little changed (37\% in both 2001 and 2002), the proportion of people receiving effective antimalarials had more than doubled to $34 \%$, demonstrating the impact of changing first line drug on the quality of treatment obtained (Kachur S.P. et al., unpublished data, IMPACT Collaboration).

A range of institutional and market-based mechanisms could in theory have protected the poorest from the costs of treatment seeking, but in practice they did not function well. In government facilities, fees were often charged for services which should have been provided free, and in government and private facilities, implementation of exemptions appeared limited and haphazard. Credit was rarely given in practice for fever/malaria treatment whether in the public or private sector, and payment-in-kind was not practised.

Hausmann-Muela et al. (2000) noted that such mechanisms were rarely implemented among biomedical care providers. By contrast, they frequently found traditional healers to accept compensation in-kind or in work, to allow payment on a credit basis, or to adjust charges to reflect the patient's economic means. Their observation that such traditional providers were very rarely used for 'normal' illnesses such as malaria was also borne out in this study.

\section{Policy Implications}

The results highlight a number of important implications for Tanzania in advance of the planned introduction of ACT in 2006. The first concerns access to antimalarials in the public sector. Based on the current use patterns, delivery through government facilities will reach only a quarter of care seekers. Expanding ACT distribution to NGO facilities would mainly increase accessibility for the better-off, with public and private facility provision reaching around one-third of those in the better-off third, but only a quarter in the poorest or middle thirds.

Provision of a more effective drug might encourage a shift in use to facilities in each SES group, but it will be important to monitor this to ascertain whether poorer groups are accessing effective treatment.

The second implication concerns the issue of extending access to ACTs beyond the public sector, as recommended by WHO and the Institute of Medicine (Institute of Medicine 2004; WHO 2004). ACT use could be increased by expanding distribution to the retail sector, potentially through drug stores, which are an established source of antimalarials and whose staff have some medical training. One might have expected poorer households to be less likely to use drug stores, but this study found use to be relatively constant across SES groups, indicating that distribution through these outlets would not reach the better-off alone. However, the study also showed that drugs were the key drivers of treatment costs in all SES groups, implying that any increase in drug cost will have a major impact on affordability for the vast majority. Achieving high ACT coverage in the retail sector even among the better-off will therefore be dependent on the provision of substantial subsidies.

A third implication concerns provision of effective treatment doses. This study has shown that under-dosing of antimalarials occurred across all SES groups. All groups should therefore be targeted with interventions to improve dosing and adherence, such as pre-packaging, improved instructions and communication. This is vital if the additional costs of ACT are to be matched by expected health outcomes.

\section{Conclusion}

The findings of our study have two key implications. Firstly, the need to improve malaria treatment is not limited to the choice of an effective first line drug. Only 
a fraction of people reporting fever, $<20 \%$ overall, received effective and adequate antimalarials. Recommendations to countries to switch to ACTs must therefore go hand in hand with strategies to improve antimalarial coverage and use. Secondly, current rates of appropriate care and treatment expenditure are positively related to SES. Our study corroborates previously reported findings on SES and care seeking, but in addition demonstrates that better-off respondents were more likely to receive effective and adequate antimalarials when compared with others. This reflected higher treatment expenditure in this group, in part because of their greater use of NGO facilities. This highlights the importance of including equity issues in debates over the choice of ACT delivery strategy. Unless we closely monitor equity outcomes and target our interventions appropriately, the poorest of the poor may fail to fully benefit from these new and highly effective medicines.

\section{Acknowledgements}

The study team is grateful for the support we received from Dr Hassan Mshinda, Director, Ifakara Health Research and Development Centre. Dr Eleuther Mwageni and Dr Rose Nathan assisted by providing access to the Rufiji and Ifakara Demographic Surveillance System data bases and personnel, respectively. The authors are further grateful for the assistance Christostom Mahutanga, Jenson Charles, Yahya Mkilindi, Ernest E. Smith, Jeffrey Schulden, Berty Farida Elling, the data collectors and participants. We are also grateful for support on writing this paper from the EQUINET-'SADC countries' doing the EQUIWRITE Workshop in Durban South Africa. Finally, this report is published with permission of the Director-General, National Institute for Medical Research, Dr Andrew Kitua. Catherine Goodman was supported by a Research Training Fellowship from the Wellcome Trust from 2001-2004 (ref. 060184), and by a Postdoctoral Fellowship from the Economic and Social Research Council from 2004-2005 (ref. PTA-026-27-0179).

\section{Disclaimer}

Trade names are used for purposes of identification only and do not constitute endorsement by the United States Public Health Service or the Centers for Disease Control and Prevention.

\section{References}

Amin AA, Marsh V, Noor AM, Ochola SA \& Snow RW (2003) The use of formal and informal curative services in the man- agement of paediatric fevers in four districts in Kenya. Tropical Medicine and International Health 8, 1143-1152.

Armstrong Schellenberg J, Victora CJ, Mushi A et al. (2003) Inequities among the very poor: health care for children in rural southern Tanzania. Lancet 361, 561-566.

Armstrong Schellenberg JR, Adam T, Mshinda H et al. (2004) Effectiveness and cost of facility-based Integrated Management of Childhood Illness (IMCI) in Tanzania. Lancet 364, 15831594.

Barat LM, Palmer N, Basu S, Worrall E, Hanson K \& Mills A (2004) Do malaria control interventions reach the poor? A view through the equity lens. American Journal of Tropical Medicine and Hygiene 71, 174-178.

Brieger WR, Osamor PE, Salami KK, Oladepo O \& Otusanya SA (2004) Interactions between patent medicine vendors and customers in urban and rural Nigeria. Health Policy Plan 19, 177182.

Clarke SE, Bogh C, Brown RC, Pinder M, Walraven GE \& Lindsay SW (2001) Do untreated bednets protect against malaria? Transactions of the Royal Society of Tropical Medicine and Hygiene 95, 457-462.

Diallo AB, De Serres G, Beavogui AH, Lapointe C \& Viens P (2001) Home care of malaria-infected children of less than 5 years of age in a rural area of the Republic of Guinea. Bulletin of the World Health Organisation 79, 28-32.

Ettling M, Steketee RW, Macheso A, Schultz LJ, Nyasulu Y \& Chitsulo L (1994) Malaria knowledge, attitudes and practices in Malawi: survey population characteristics. Tropical Medicine and Parasitology 45, 57-60.

Filmer D (2002) Fever and Its Treatment Among the More and Less Poor in Sub-Saharan Africa. World Bank Development Research Group, Washington DC.

Filmer D \& Pritchett L (2001) Estimating wealth effects without expenditure data - or tears: with an application to educational enrollements in states of India. Demography 38, 115-132.

Hausmann Muela S, Mushi AK \& Muela Ribera J (2000) The paradox of the cost and affordability of traditional and government health services in Tanzania. Health Policy and Planning 15, 296-302.

INDEPTH Network (2002) Population and Health in Developing Countries. Volume 1 Population, Health, and Survival at INDEPTH Sites. International Development Research Centre, Ottawa.

Institute of Medicine (2004) Saving Lives, Buying Time: Economics of Malaria Drugs in an Age of Resistance. National Academies Press, Washington DC.

Kachur SP, Khatib RA, Kaizer E, Fox SS, Abdulla SM \& Bloland PB (2004) Adherence to antimalarial combination therapy with sulfadoxine-pyrimethamine and artesunate in rural Tanzania. American Journal of Tropical Medicine and Hygiene 71, 715-722.

Malaria Consortium (2004) Tanzania Roll Back Malaria Consultative Mission (Reaping): Essential Actions to Support the Attainment of the Abuja Targets. DFID, London.

McKenzie DJ (2003) Measuring Inequality with Asset Indicators. BREAD Working Paper No. 042. Bureau for Research in Economic Analysis of Development, Stanford, CA. 
J. D. Njau et al. Fever treatment and household wealth

Measure DHS (2005) Demographic and Health Surveys. Basic Documentation. MACRO International, http://www.measuredhs.com/methodology/basic_doc.cfm

Ministry of Health (1999) Summary report of the Task Force on Antimalarial Drug Policy, July 23, 1999. Ministry of Health, United Republic of Tanzania, Dar es Salaam, pp. 1-5.

Minja H, Schellenberg JA, Mukasa O et al. (2001) Introducing insecticide-treated nets in the Kilombero Valley, Tanzania: the relevance of local knowledge and practice for an information, education and communication (IEC) campaign. Tropical Medicine and International Health 6, 614-623.

Mullahy J (1998) Much ado about two: reconsidering retransformation and the two-part model in health econometrics. Journal of Health Economics 17, 247-281.

National Bureau of Statistics Tanzania, Macro International Inc. (2000) Tanzania Reproductive and Child Health Survey 1999. National Bureau of Statistics and Macro International Inc., Calverton, Maryland.

Rashed S, Johnson H, Dongier P et al. (2000) Economic impact of febrile morbidity and use of permethrin-impregnated bed nets in a malarious area II. Determinants of febrile episodes and the cost of their treatment and malaria prevention. American Journal of Tropical Medicine and Hygiene 62, 181-186.

Stata Inc. (2003) Survey Data Reference Manual. Stata Press, College Station, TX, USA.

Tarimo DS, Lwihula GK, Minjas JN \& Bygbjerg IC (2000) Mothers' perceptions and knowledge on childhood malaria in the holendemic Kibaha district, Tanzania: implications for malaria control and the IMCI strategy. Tropical Medicine and International Health 5, 179-184.

UNICEF (2005) Multiple Indicator Cluster Survyes. UNICEF, http://www.childinfo.org/MICS2/Gj99306k.htm

United Republic of Tanzania - National Bureau of Statistics (2003) Tanzania Household Budget Survey 2000/01. GOT, Dar-es-Salaam, pp. 1-115.

White NJ, Nosten F, Looareesuwan S et al. (1999) Viewpoint: averting a malaria disaster. The Lancet 353, 1965-1967.

WHO (2003) Protocols and Methods for Roll Back Malaria Situation Analysis. WHO, Geneva.

WHO (2004) Scaling Up Home-Based Management of Malaria. Roll Back Malaria Department/UNICEF/UNDP/World Bank/ TDR WHO/HTM/MAL/2004.1096, Geneva.

WHO/UNICEF (2003) Prompt and Effective treatment - The African Malaria Report, WHO/COS/UNICEF/MAL/2003. WHO, Geneva and UNICEF, New York, pp. 31-37.

Winch PJ, Makemba AM, Kamazima SR et al. (1994) Seasonal variation in the perceived risk of malaria: implications for the promotion of insecticide-impregnated bed nets. Social Science and Medicine 39, 63-75.

Winch PJ, Makemba AM, Kamazima SR et al. (1996) Local terminology for febrile illnesses in Bagamoyo District, Tanzania and its impact on the design of a community-based malaria control programme. Social Science and Medicine 42, 10571067.

Corresponding Author Joseph D. Njau, Ifakara Health Research and Development Centre, PO Box 78373, Dar es Salaam, Tanzania. Tel.: +255-222-774-714; Fax: +255-222-771-714; E-mail: jnjau@ihrdc.or.tz or joseph.don@gmail.com

Traitement de la fièvre en fonction des moyens de la famille: le défi posé pour exclure la thérapie combinée dans la malaria

OBJECTIF Investiguer les variations dans la parasitémie de la malaria, les fièvres rapportées, les recours aux soins, les antimalariques obtenus et les dépenses des familles selon le statut socio-économiques, et évaluer les implications dans l'assurance d'une utilisation équitable et appropriée de la thérapie antimalarique combinée.

мÉтHOdes 2500 familles ont été étudiées dans 3 districts ruraux dans le sud de la Tanzanie au milieu de l'année 2001. Des échantillons de sang et les données sur le statut socio-économique ont été collectés dans toutes les familles. Une moitié des participants a complété un questionnaire détaillé sur le recours aux soins et le coût des traitements. Les familles ont été reparties par catégories selon le statut socio-économique sur base d'un index de richesse de famille dérivant d'analyse de composant principaux.

RÉSULTATS $16 \%$ des individus ayant complété le questionnaire détaillé ont rapporté un épisode de fièvre au cours des deux semaines précédentes. Les personnes dans la catégorie à moyens élevés avaient significativement moins de parasitémie et étaient significativement plus susceptible d'obtenir des antimalariques comparées à celles dans les catégories intermédiaires ou pauvres. Un meilleur traitement coûtait aux personnes de la catégorie à moyens élevés 2-3 fois plus cher que pour les personnes dans les catégories intermédiaires et pauvres. Ceci reflète un recours plus élevé aux services des ONG qui sont plus coûteux et donc une plus grande dépense dans les services des ONG et dans les dépôts pharmaceutiques.

CONCLUSION La couverture d'un traitement approprié de la malaria était basse quel que soit le statut socio-économique du groupe. Mais, les deux catégories les plus pauvres étaient particulièrement désavantagées. A l'heure où les pays se tournent vers une thérapie combinée de la malaria, la distribution des médicaments devrait être ciblée afin de s'assurer que les plus pauvres puissent bénéficier de ces nouveaux médicaments très actifs.

mots clés malaria, antimalariques, thérapie combinée, statut socio-économique, équité, famille 


\section{J. D. Njau et al. Fever treatment and household wealth}

Tratamiento de la fiebre y patrimonio familiar: el reto que supone el poner en marcha la terapia de combinación para malaria

OвJETIvo Investigar la variación en la parasitemia de malaria, la fiebre reportada, la búsqueda de cuidados de salud, los antimaláricos obtenidos y el gasto familiar por estatus socio-económico, y evaluar las implicaciones para asegurar un uso equitativo y apropiado de la terapia de combinación para la malaria.

мÉTODO Se entrevistaron 2500 hogares en tres distritos rurales del sur de Tanzania a mediados del 2001. Se tomaron muestras de sangre y datos sobre el estatus socio-económico de todos los hogares. La mitad completó un cuestionario detallado sobre la búsqueda de cuidados y los costes de tratamiento. Las familias se catalogaron según su estatus socio-económico basándose en un índice de riqueza familiar obtenido con un análisis de componentes principales.

RESultados De los individuos que completaron el cuestionario detallado, un 16\% reportó un episodio de fiebre en las dos semanas anteriores. Las personas del estrato social más elevado tenían significativamente una probabilidad mas baja de ser parasitémicos y una probabilidad más alta de obtener antimaláricos, que aquellos en los estratos medio o bajo. El mejor tratamiento cuesta al menos dos a tres veces más que lo gastado por los estratos medio y bajo. Esto refleja un mayor uso de instalaciones de ONG, que eran la fuente de cuidados más costosa, y un mayor gasto en las instalaciones de las ONG y las farmacias.

CONCLUSIón La cobertura de un tratamiento apropiado para la malaria era baja en todos los estratos socio-económicos, pero los dos más pobres estaban particularmente en desventaja. A medida que los países hacen el cambio a una terapia de combinación, la distribución debe ser focalizada, con el fin de asegurar que los grupos más pobres se benefician plenamente de estos medicamentos nuevos y altamente eficaces.

palabras clave malaria, antimaláricos, terapia de combinación, estatus socio-económico, equidad, familias 